\title{
THE NEW SISMIMUR PLAN: SEISMIC URBAN PLANNING IN THE REGION OF MURCIA (SPAIN) AFTER THE EARTHQUAKE OF MAY 11, 2011
}

\author{
S. GARCÍA-AYLLÓN \& A. TOMÁS \\ Department of Civil Engineering, Technical University of Cartagena (UPCT), Spain.
}

\begin{abstract}
The Lorca earthquake of May 11, 2011, was a traumatic yet very instructive experience for the Region of Murcia. Despite its limited scale of only 5.1 Mw, the earthquake caused nine deaths and material damage valued at over 800 million Euros in a city of just 100,000 inhabitants. This catastrophic result has led the regional government to implement a new plan, SISMIMUR, to better foresee and manage future earthquakes. In a move to improve the response to earthquakes, the new plan will incorporate innovative approaches to seismic engineering, creating aftershock evaluation protocols for buildings and the implementation of urban planning to reduce seismic vulnerability in the territorial development of cities. In these fields, the government of the Region of Murcia has commissioned the Technical University of Cartagena to conduct an urban microzonation in the city of Lorca as a pilot project to incorporate its findings to the future plan SISMIMUR. This article summarizes the main advances achieved in this research project and their possible contributions to the SISMIMUR plan.

Keywords: Seismic planning, SISMIMUR, urban microzonation, aftershock building evaluation, urban planning and management, zoning of seismic damage.
\end{abstract}

\section{LESSONS LEARNED FROM THE LORCA EARTHQUAKE OF MAY, 2011}

The earthquake of May 11, 2011, caused extensive damage in the city of Lorca. Apart from the loss of nine lives (Fig. 1), very substantial damage will force the reconstruction of the entire city over several years. However, the distribution of this damage has important peculiarities, which must be analysed.

Firstly, it is important to establish which elements were finally damaged. In the case of human lives lost, it must be pointed out that none of these deaths were generally due to the direct collapse of the buildings, which they were in. Most were caused by detachment or phenomena associated to non-structural elements such as sills or coatings of the buildings that fell onto people who were in the street (Table 1).

With regard to damage, it is important to highlight the difference between the damage to buildings and to infrastructures (Table 2). In the case of the infrastructure, the damage was

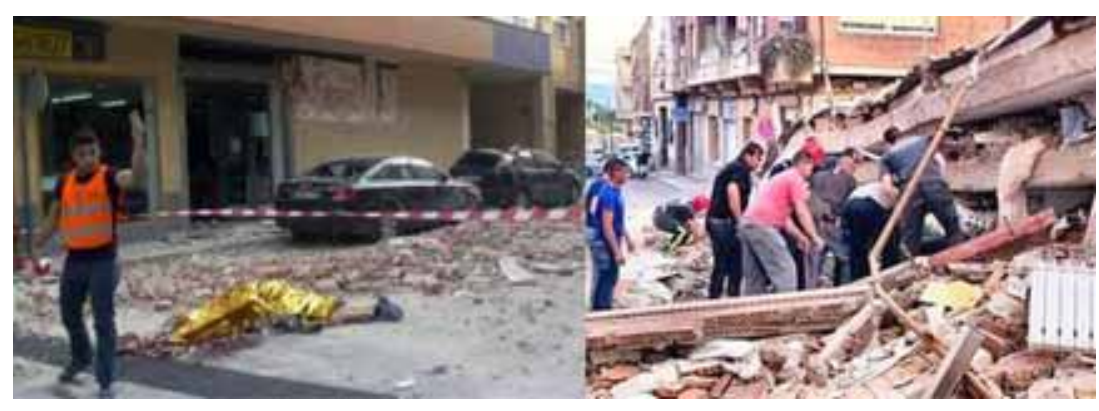

Figure 1: Victims occurred during the earthquake of 2011. Source: EFE press. 
Table 1: Breakdown of victims by cause.

\begin{tabular}{lc}
\hline Cause of death & Victims (\%) \\
\hline Collapse of the structure that housed the victim & $1(11 \%)$ \\
Consequence of the collapse of the structure on the victim & $2(22 \%)$ \\
Projection/detachment of non-structural elements & $6(67 \%)$ \\
\hline
\end{tabular}

Source: Authors, UME.

Table 2: Summary of difference in damage between infrastructure and buildings.

Infrastructure

\begin{tabular}{ll}
$\begin{array}{l}\text { Roads, highways } \\
\text { Bridges, tunnels }\end{array}$ & $\begin{array}{l}\text { Widespread minor damage. } \\
\text { Minor damage, the tunnels were closed to traffic for } \\
\text { two hours. } \\
\text { Mams, hydraulic networks } \\
\text { and sewerage. } \\
\text { Railways }\end{array}$ \\
\hline Buildings & \begin{tabular}{l} 
No damage. \\
\hline Old town, historical buildings \\
Technological constructions
\end{tabular} \\
& $\begin{array}{l}\text { Only one building collapsed during the quake. Over } \\
1,500 \text { homes had to be demolished in the following } \\
\text { months because of the damage. }\end{array}$ \\
\hline
\end{tabular}

Source: Authors.

almost negligible: The bridges of the city remained in service without any problems, the roads did not suffer any displacement, water pipes and dams registered only a few breaks in the smallest urban sewerage networks without ever interrupting its global service, the tunnels to enter the city registered only small cracks, and railroad tracks suffered only minor damage (very little compared to what they would suffer four months later during the floods caused by the usual autumn rainfall, which forced an interruption in the service for several months).

In the case of buildings, the damage was substantial. The construction and structural pathologies caused by the earthquake reveal a diverse range of deficiencies in the design, implementation, and even in the urban planning of the buildings in Lorca.

Firstly, the historic buildings are considered, those whose construction process was prior to any technological procedures of seismic regulations, and whose location precedes the urban planning of the city. It should be noted that the narrowing of Guadalentin River, where the town of Lorca lies, has been a site chosen since ancient times to ford the river, thus making it a privileged communication node during centuries. But these privileged conditions of the site are really due to the activity of the Alhama Fault, characterized by a high escarpment 

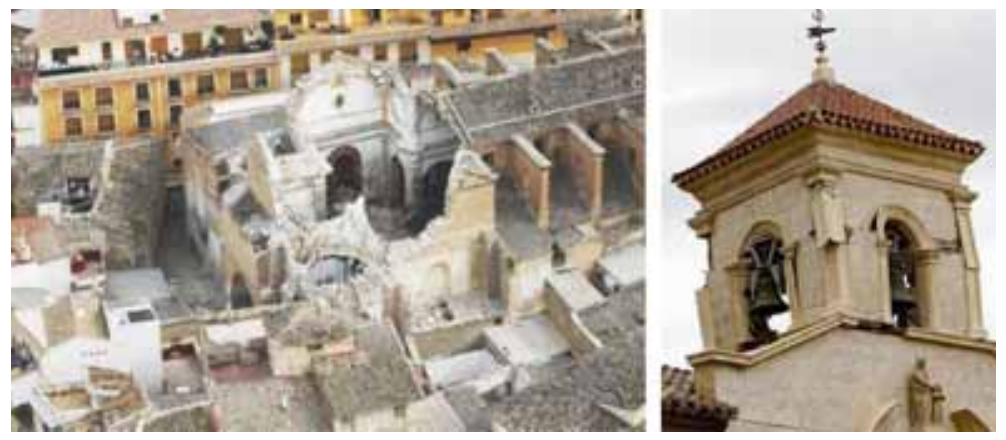

Figure 2: Historical buildings damaged in Lorca. Source: Authors.

that affords excellent visibility and security to the population. However, as a result of the fault, in 1674 an earthquake caused extensive damage to the city, marking the beginning of a major reconstruction programme, which is reflected in the current existence of a large urban baroque plot with buildings from the 17th and 18th century [1].

This historic urban plot was one of the most damaged by the earthquake (Fig. 2). Such a situation can be considered somewhat predictable. The old town of Lorca was composed mainly of stone wall structures with wooden floors. Thus, there was no diaphragm effect in these structures to make them more rigid.

In Europe, among the existing methods to classify the vulnerability of buildings, those based on macroseismic scales are the most widespread. These scales classify vulnerability in an approximately linearly downward manner and in varying degrees from A to F. The aforementioned types of historic buildings in Lorca would be considered highly vulnerable (A, B) in EMS98 macroseismic scales due to their large mass and low embedment between the wall planes. This EMS98 scale defines the degree of fragility of a building against seismic action (meaning that the more vulnerable a building is, the greater tendency it will have to be damaged), with a so-called 'mean damage index'. It is an indicator of the average damage for a certain population and class of vulnerability:

$D_{m}=\sum_{i}^{1} d_{i} N_{i} / N$, with $N_{i}$ being the number of buildings with damage $i$ for a given vulnerability class population $d$ and $N$ is the total number of buildings for the same class and population. The variability range is similar to the degree of damage on the scale adopted. If the damage is measured on the EMS-98 scale, $D_{m}$ ranges from 0 to 5 .

In the case of Lorca, where the value of $D_{m}$ would in theory be between 3.5 and 4.5 for the old town [2], we note that in the plot of historical and noteworthy buildings such as churches, and a part of the 19th century plot, the buildings have brick masonry that improves the embedding between wall planes and reduces the mass of the building. These are therefore considered as less vulnerable than traditional masonry buildings. This, however, did not prevent many of them from collapsing during the earthquake of moderate intensity in $2011[1]$.

In the case of existing buildings already constructed with frameworks of beams and columns, we find a wide range of causes. First, it cannot be stated that the more modern buildings (and therefore theoretically more suited to seismic regulations) are the most resilient. The only building that collapsed during the earthquake was only eight years old and was thus theoretically adapted to the latest Spanish seismic code (NCSE-02). 

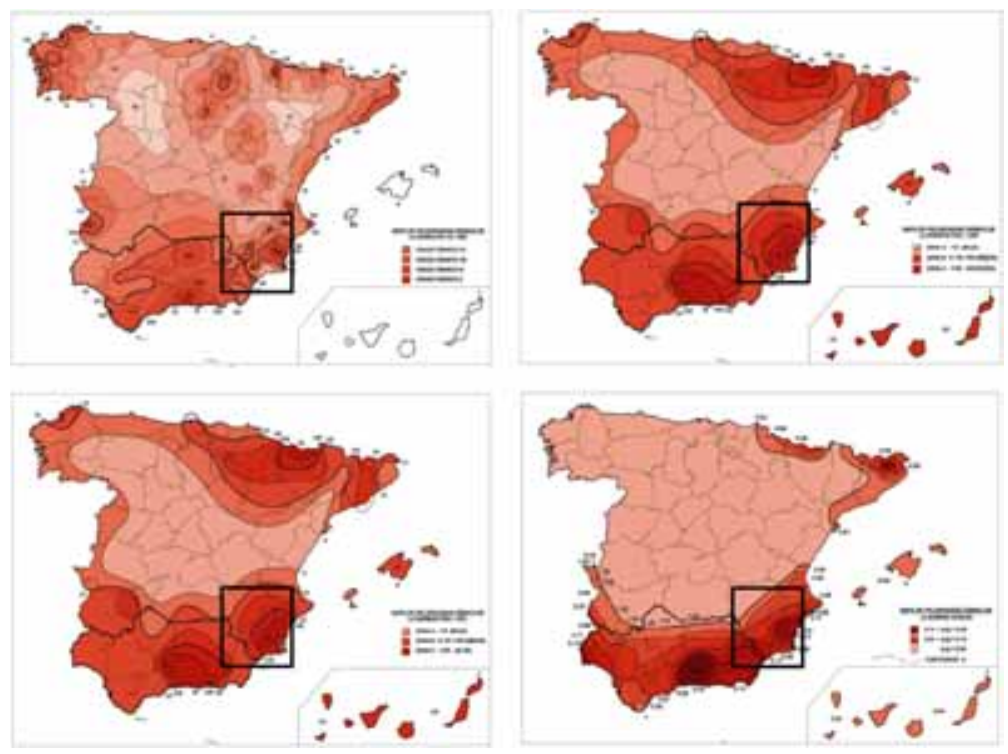

Figure 3: Evolution of the seismic hazard map in the Region of Murcia according to MV-101, PGS-1, PDS-1, NCSE-94 and NCSE-02. Source: Ministry of Public Works of Spain [3].

In Spain, since the mid-twentieth century, seismic standards are mandatory in building projects. It is a reasonable starting point to differentiate traditional building (that based only on good construction practices) from technological building (where the stresses on structures are defined and calculated). The last 50 years have seen an important evolution of the methodology for seismic Spanish regulations (MV-101 (1962), PGS-1 (1968), PDS-1 (1974), NCSE-94 (1994) and NCSE-02 (2002)). Nevertheless, in all these rules, the Region of Murcia remains one of the most dangerous seismic territories, although the area of the city of Lorca is not designated as an environment of maximum intensity (Fig. 3).

In the latest seismic regulations, NCSE-02, the town of Lorca was assigned a basic acceleration (seismic design governing parameter in the Spanish rules) of $0.12 g$ (Fig. 4). This value, under the assumption of the worst local hypothesis, could lead to a calculation acceleration of $0.196 \mathrm{~g}$. However, the acceleration produced during the earthquake in 2011 was $0.369 \mathrm{~g}$, much higher than the expected value in the standard, which requires us to rethink previous assumptions and propose new hypotheses. These values obtained on the basis of macroseismic studies show the need to increase the weight of the local factor analysis and also to take into account new parameters such as urban planning or the state of the housing stock in the model. These new methods are being implemented in the Lorca urban microzonation study, commissioned by the Ministry of Public Works and Territory of the Region of Murcia to the Technical University of Cartagena.

However, the most common structural pathologies in the Lorca earthquake did not generally come from bad calculation or poor execution of the structure. Besides the mentioned damaged walls and parapet detachments, the most common phenomena in buildings damaged because of the earthquake were short columns, soft floors, and pounding (Fig. 5). 


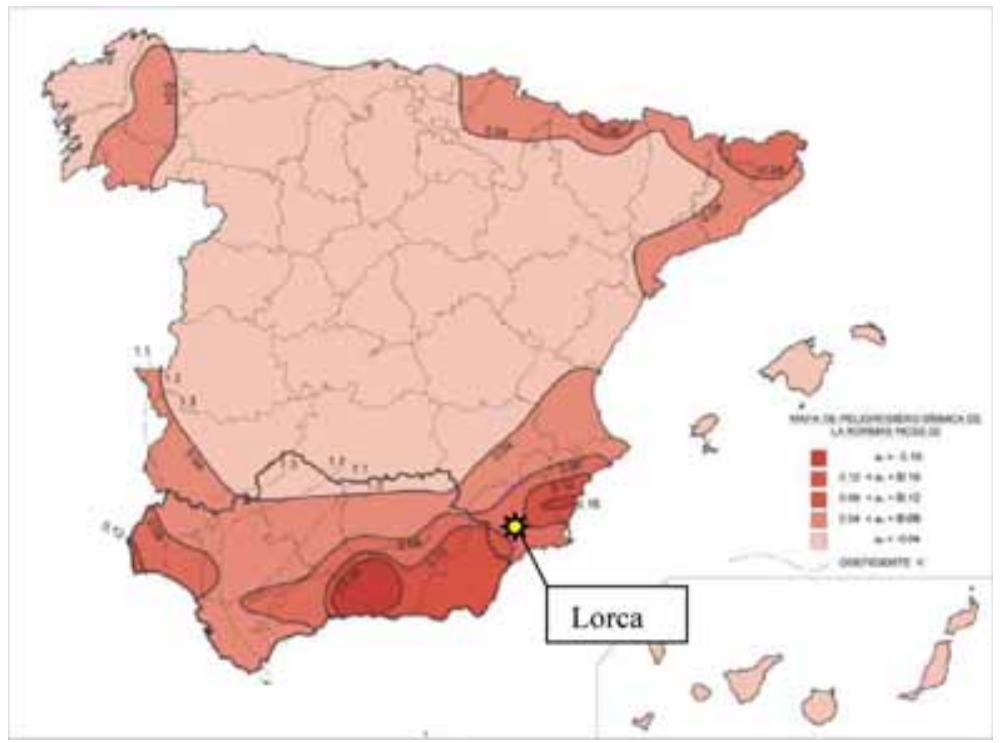

Figure 4: Status of Lorca in the seismic intensity map of NCSE-02 standard. Source: [3-6].
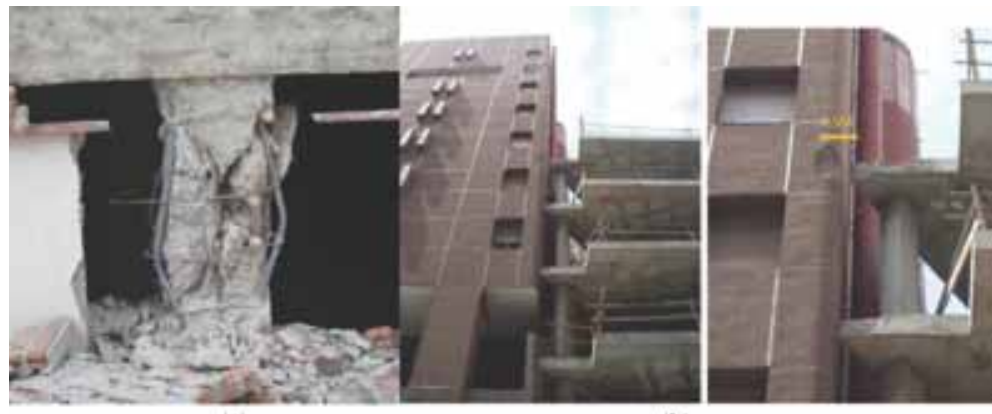

(a)

(b)

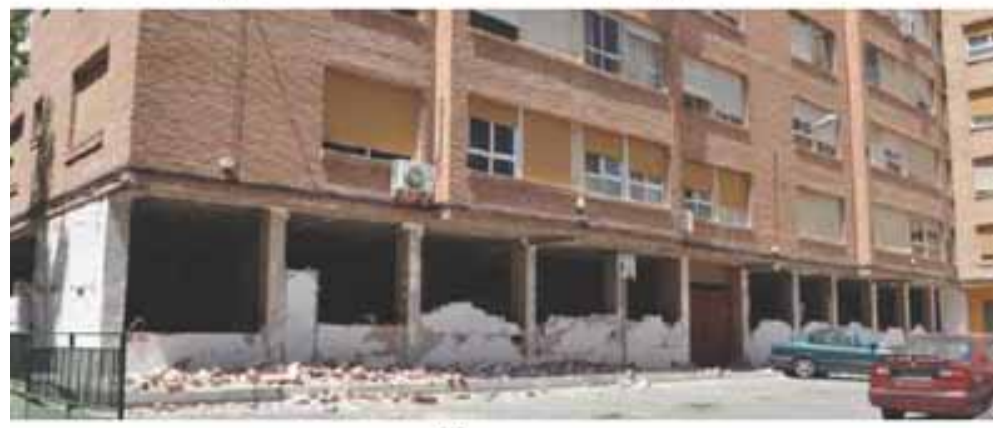

(c)

Figure 5: Damage from (a) short columns, (b) pounding and (c) soft floors. Source: Authors; Cartagena Fire Department. 


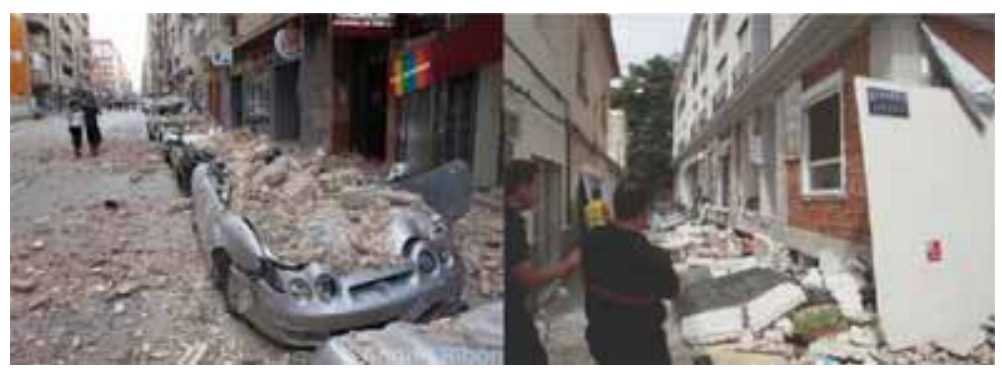

Figure 6: Detachments due to lack of bracing parapets as recommended by NCSE-02 (left) and inefficient building design (right). Source: Andrés Ribón; Authors.

These issues, shown up by the earthquake, respond to reasons related to inadequate design of the building or lack of implementation of some of the constructive recommendations of the seismic standards (Fig. 6). Nevertheless, we also find unexpected derivatives in the damage analysis such as the existence of urban planning, which did not take into account the seismic vulnerability of the city of Lorca, placing buildings on unsuitable land, on complex orography, or with unsatisfactory distances between buildings.

\section{THE IMPACT OF URBAN PLANNING IN THE ANALYSIS OF EARTHQUAKE DAMAGE.}

If we make a simple spatial analysis of damage distribution in the city of Lorca after the earthquake in May 2011, we can extract two very clear conclusions (Fig. 7):

- First, damage distribution is not homogeneous: material damage and casualties are mainly concentrated in seven or eight specific points geographically scattered around the city.

- Second, it is paradoxical that the epicentres of the two seismic shocks are not important points for damage (neither the infrastructure nor the few houses near the epicentre area suffer severe damage). In fact, the neighbourhood of La Viña (the 'ground zero' of the earthquake) is one of the most distant points of the city from the epicentres.

These asymmetric distributions led us to think of a principle derived from a geotechnical nature in response to this phenomenon. Indeed, the nature and distribution of soil quality responds to a certain extent to some of the effects occurring. If we make a geographical survey of the main local parameterization factor of seismic regulations NCSE-02 (the amplification factor C), some of the damage in the city can be explained (Fig. 8).

The San Fernando district was a neighbourhood with 232 homes [7] consisting of nine buildings built in the 1970s (Fig. 9). The existence of land fillings composed of sedimentary deposits from the Guadalentin River with amplification factor $\mathrm{C}=1.98$, and the existence of soft story buildings that favoured the phenomenon of 'soft floor', caused severe damage, forcing all nine buildings of the district to be demolished (Fig. 10).

Nevertheless, if we overlay a basic plot of damaged buildings (damaged, very damaged, and demolished) over the geotechnical characteristics of land distribution set by the Spanish standard (I, II, III and IV), the results about this relationship remain inconclusive (Fig. 11). Thus, there are other variables that may help to explain the asymmetry of the damage that followed the earthquake. 


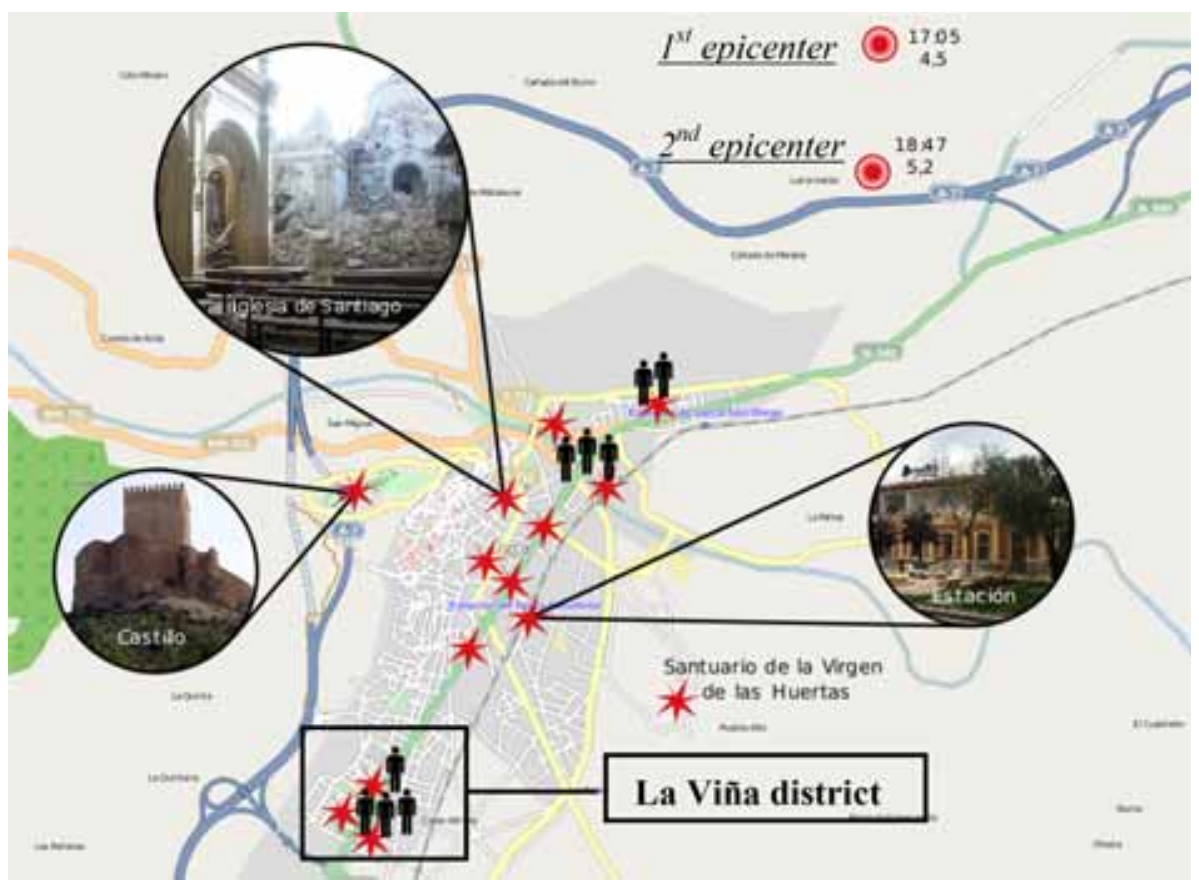

Figure 7: Schematic distribution of damage and casualties in the city of Lorca. Source: Google OpenStreetMap. Modified by authors.

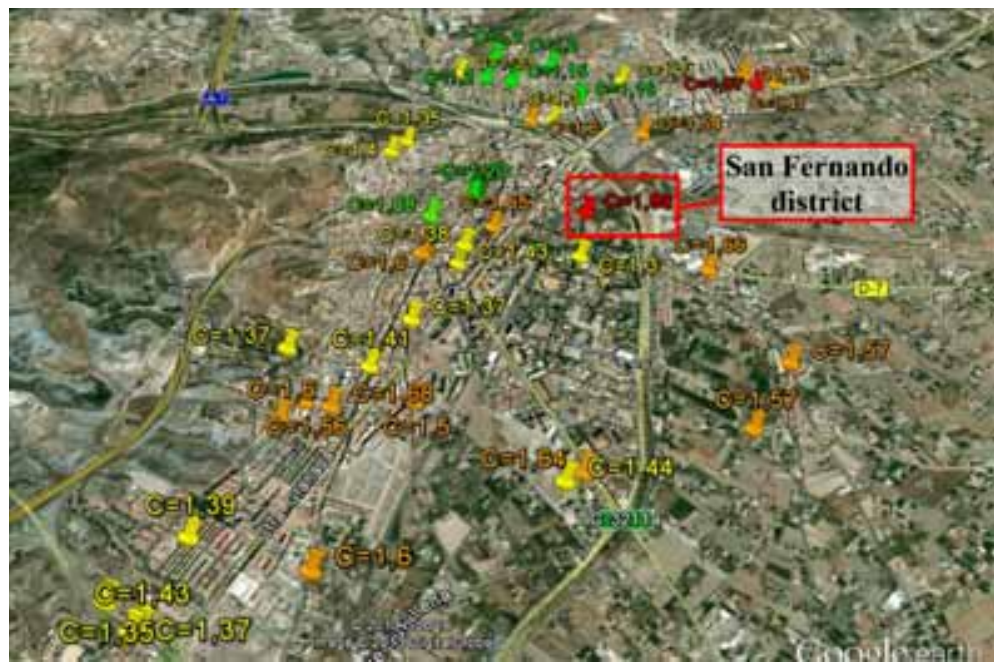

Figure 8: Inventory of C parameters in the city of Lorca according to geotechnical studies of constructions. Source: Authors. 


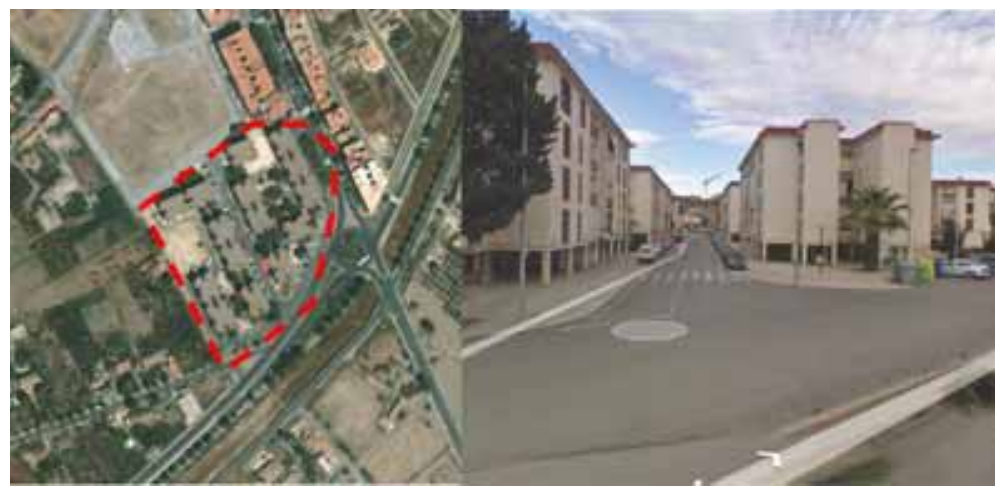

Figure 9: Situation of the San Fernando district in Lorca (left) and state prior to the earthquake (right). Source: Google Earth.

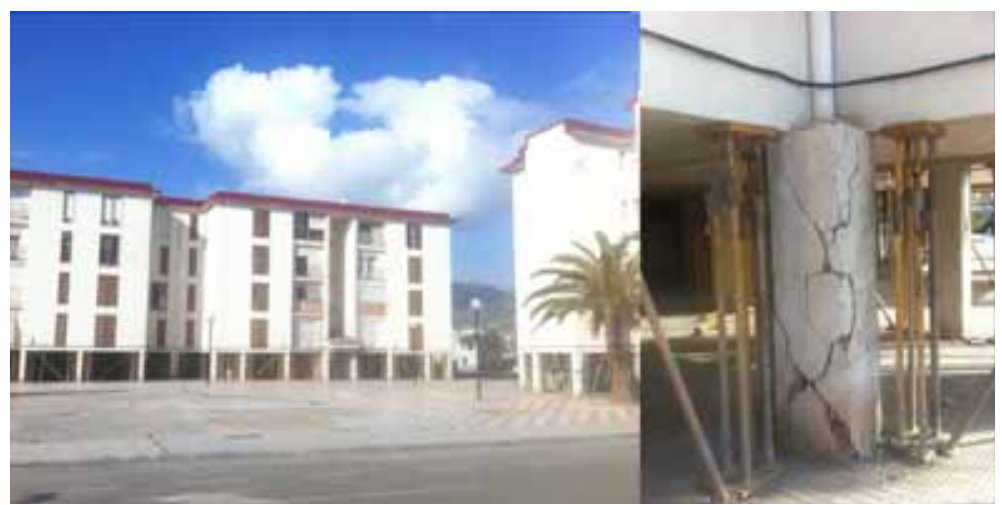

Figure 10: San Fernando district after the quake (left) and state of the columns on the ground floor (right). Source: Authors.

A variable that should start to be implemented in the analysis of global damage of a city is the incidence of the inadequate urban planning of its buildings. In the case of Lorca, where, as we have seen, damage was concentrated in buildings and not in infrastructures, it can be seen how the urban planning of the city did not take into account the variable of seismic risk. Some causes of construction execution or design that have been identified in the previous section as negative in an earthquake are often the result of inadequate urban planning.

In the case, for example, of the only building that collapsed during the shock (a building which was only eight years old, and therefore theoretically adapted to the latest seismic code), the cause of the collapse has been attributed to the existence of short columns in its base. However, this configuration of short columns is the result of an urban design forced by the layout of the streets in a recent expansion of the city (Fig. 12). The sloping design of the streets and the existence of garages on the ground floor generated columns of 


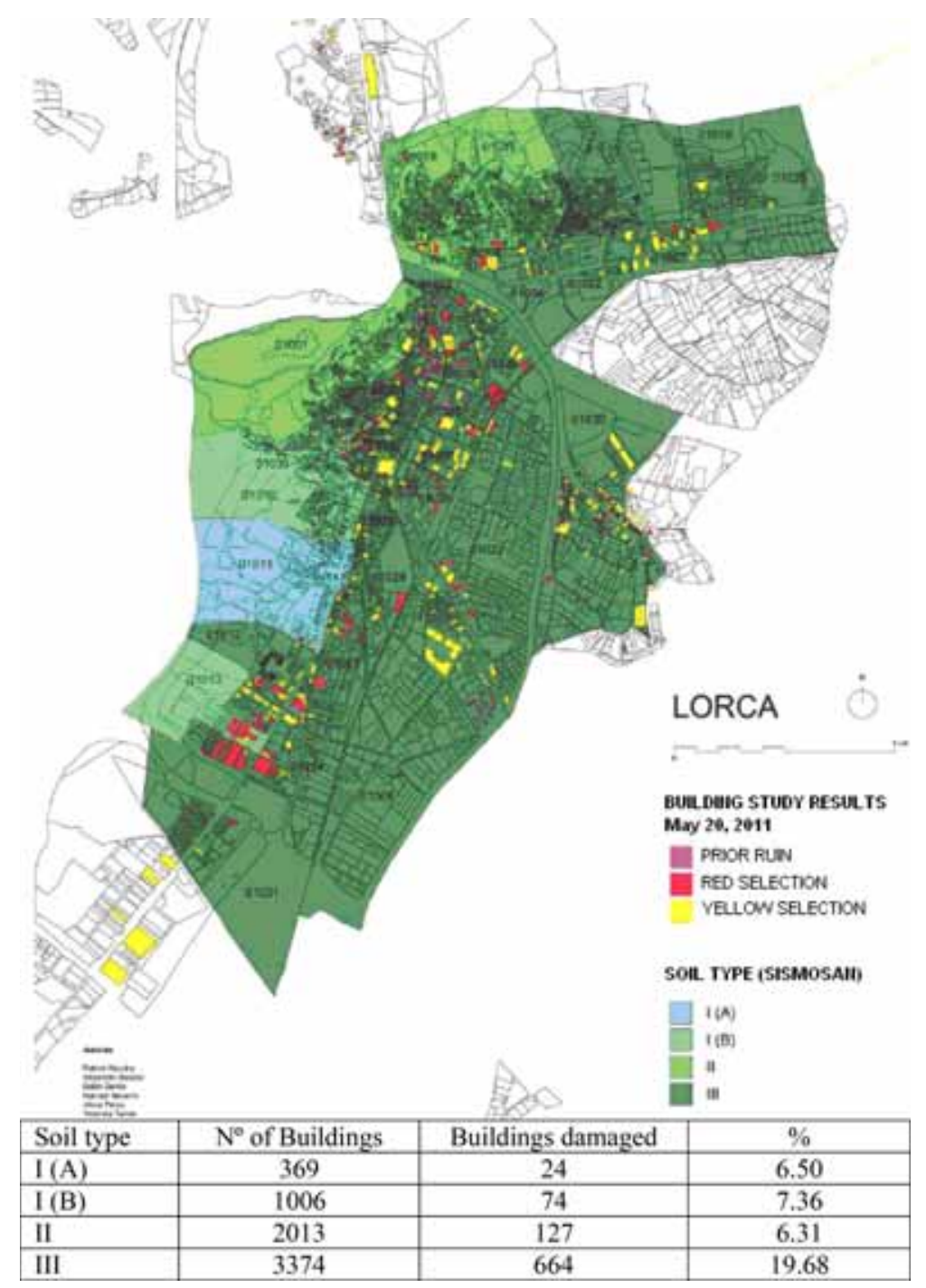

Figure 11: Distribution of damage by ground type distribution according to the standard. Source: [8].

different heights on the ground floor (Fig. 13). These columns, extending from the concrete walls of the garage, included a short space where significant deformation tensions were concentrated due to the accumulation of shear stresses. This situation created a space of weakness in the ground floor that proved to be fatal during the earthquake, making the building collapse. This hypothesis is underpinned by the analysis of adjacent buildings to that which collapsed. Those buildings located in the same sloping streets suffered from the same pathologies as the collapsed one, with their short columns being close to collapse (Fig. 14). 


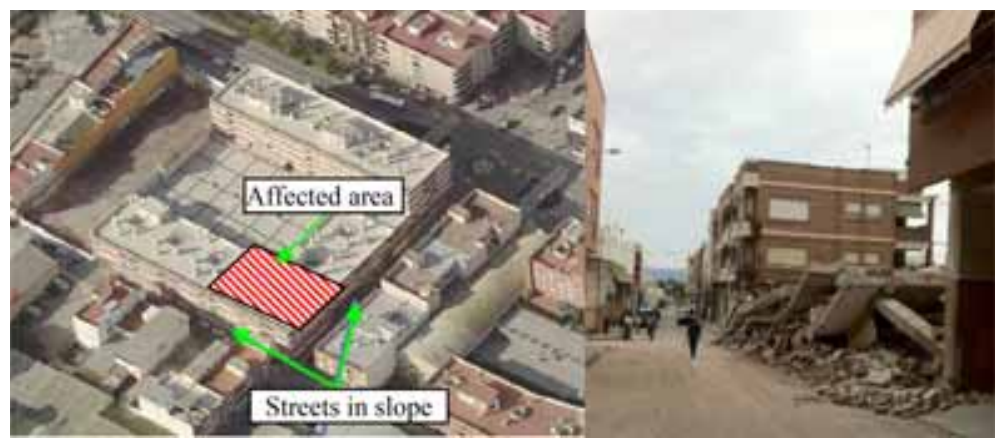

Figure 12: Location of the building collapsed in the neighbourhood of La Viña (left) and view from the beginning of the street after collapsing (right). Source: Authors.

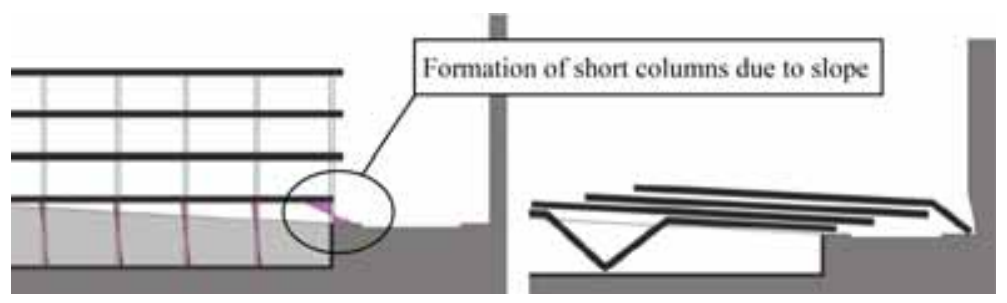

Figure 13: Schematic formation of short columns (left) and collapse of the building (right). Source: [1].

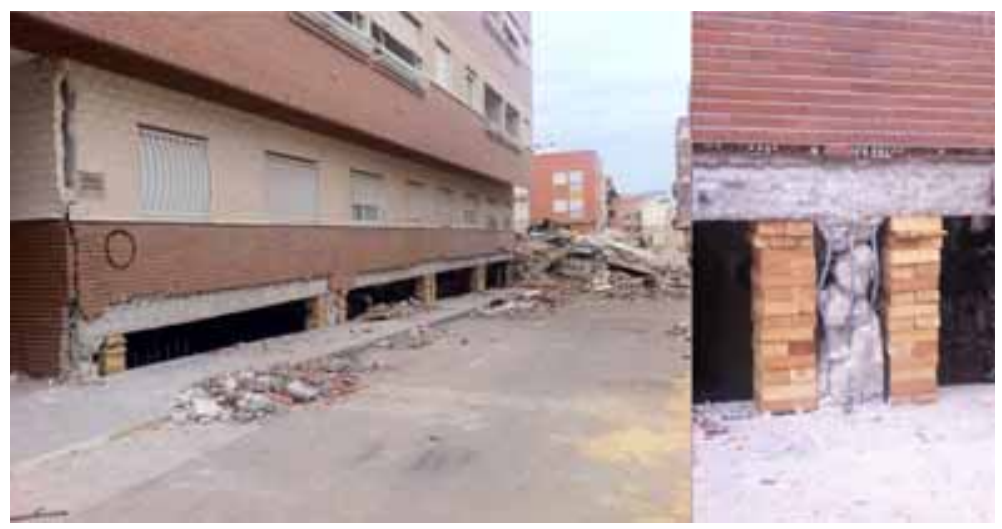

Figure 14: Situation of a building next to the collapsed one (left) and status of its short columns (right). Source: Authors.

There are also other conditions which arose in the earthquake with urban origins such as pounding or the interaction between buildings because of the different resonance frequencies generated by the differences in height (Fig. 15). The conformation method of the urban plot must therefore be a variable to take into account in seismic planning, in the same way that urban management tools have to implement seismic guidelines in their content. 

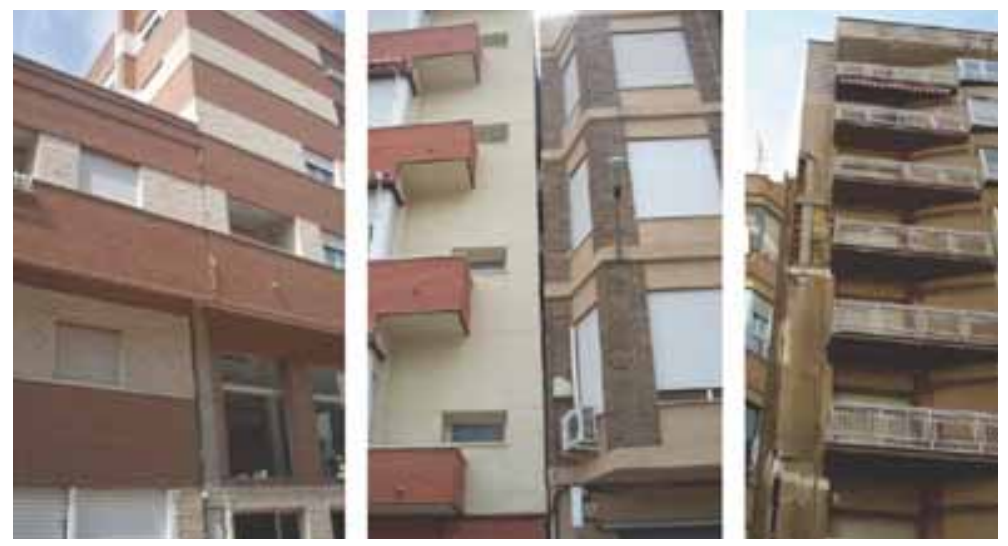

Figure 15: Different cases of buildings in Lorca with pounding and interaction between buildings due to height difference. Source: Authors.

\section{NEW EVALUATION TECHNIQUES FOR INFORMATION AND AFTERSHOCK MANAGEMENT}

One of the main lessons the Region of Murcia has learnt from the earthquake in Lorca is the importance of knowing how to manage the first moments after the quake. In this field, one of the main actions is certainly that of performing a correct aftershock diagnosis.

We must bear in mind that in an event of this nature, the problems are serious and numerous, and resources are often limited. In an earthquake like Lorca 2011, there can be hundreds or even thousands of damaged buildings, with very different levels of damage. Initially, it may be acceptable to force all people to leave their homes (regardless of the danger that this entailed in the case of Lorca, where the facade and parapet detachments claimed lives). However, after a few days, it is unsustainable for people not to return to their homes.

The city can be partially evacuated during the first hours (especially due to the panic created and to possible aftershocks). Therefore, there are a number of hours (between 24 and 48 hours after the earthquake), in which a technical intervention is necessary for a diagnostic at a global scale. The diagnosis must be fast and must ensure safety to the owners, despite limited resources.

Human resources are initially very limited, since the authorities are scarcely able to find enough qualified professionals with experience in this kind of phenomena. In Lorca 2011, apart from the specialists of the administration emergency services (technicians, firefighters, etc.), technicians from the whole region (engineers, architects) were voluntarily summoned through professional associations. These technicians were a very heterogeneous group of architects and engineers with different categories and levels of knowledge. In general, most of them had basic knowledge of seismic issues but had not received enough specific training.

The logical scarcity of material added to this problem. Diagnoses were only made by visual inspection because of the impossibility to perform tests or other verifications in that context. We were therefore witness to a situation that required solving a complex problem quickly, which was none other than to assess the structural damage of a building, with the additional difficulty of a significant shortage of human and material resources. Around 20 technical groups were created in Lorca, which covered the different neighbourhoods of the city. The buildings were marked with a green, yellow, or a red code. 
This methodology has been usual in recent urban earthquakes all over the world. However, as happened in Lorca, there is a problem due to the lack of standardized protocols and classifications, in enabling a homogeneous and safe diagnosis. In this regard, we observe that among the major urban earthquakes in the last three decades, we do not find clear common criteria (Table 3):

Table 3: Damaged building classification categories.

\begin{tabular}{|c|c|c|c|}
\hline & $\begin{array}{l}\text { GREEN } \\
\text { (safe, usable, or } \\
\text { habitable) }\end{array}$ & $\begin{array}{l}\text { YELLOW } \\
\text { (caution, restricted } \\
\text { entry, or temporary } \\
\text { disablement, dubious } \\
\text { safety) }\end{array}$ & $\begin{array}{l}\text { RED } \\
\text { (risk, unsafe, or } \\
\text { disablement) }\end{array}$ \\
\hline $\begin{array}{l}\text { Japan } \\
(1986)\end{array}$ & Access allowed. & $\begin{array}{l}\text { Access allowed after } \\
\text { taking some } \\
\text { precautions. }\end{array}$ & $\begin{array}{l}\text { Access forbidden. } \\
\text { Danger in non-structural } \\
\text { elements. }\end{array}$ \\
\hline $\begin{array}{l}\text { USA } \\
(1995)\end{array}$ & $\begin{array}{l}\text { Damage does not } \\
\text { represent any danger. } \\
\text { It does not imply some } \\
\text { need of reparation. }\end{array}$ & $\begin{array}{l}\text { Restricted occupation } \\
\text { of damaged areas and } \\
\text { during a certain period } \\
\text { of time. Other areas } \\
\text { not possible/non- } \\
\text { habitable with normal } \\
\text { conditions. }\end{array}$ & $\begin{array}{l}\text { Immediate risk } \\
\text { associated to entry, } \\
\text { occupation, or use. } \\
\text { It does not imply } \\
\text { demolition of the } \\
\text { building. }\end{array}$ \\
\hline $\begin{array}{l}\text { Turkey } \\
\text { (1999) }\end{array}$ & $\begin{array}{l}\text { Little or no structural } \\
\text { damage. } \\
\text { Temporary occupation } \\
\text { allowed. }\end{array}$ & $\begin{array}{l}\text { Damage to structural } \\
\text { and/or non-structural } \\
\text { elements. } \\
\text { Temporary occupation } \\
\text { not allowed, except for } \\
\text { emergencies. }\end{array}$ & $\begin{array}{l}\text { Significant risk of } \\
\text { collapse with after- } \\
\text { shocks. } \\
\text { Entry not allowed. } \\
\text { Measures to prevent } \\
\text { sudden collapse. }\end{array}$ \\
\hline $\begin{array}{l}\text { Colombia } \\
(2009)\end{array}$ & $\begin{array}{l}\text { Low risk for global } \\
\text { stability, geotechnical } \\
\text { problems, structural } \\
\text { damage and/or non- } \\
\text { structural damage. }\end{array}$ & $\begin{array}{l}\text { Low risk, after } \\
\text { measurements, global } \\
\text { stability, geotechnical } \\
\text { problems, structural } \\
\text { damage, and/or non- } \\
\text { structural damage. }\end{array}$ & $\begin{array}{l}\text { High risk for at least } \\
\text { two (or very high } \\
\text { for at least one) of } \\
\text { the following rea- } \\
\text { sons: global stability, } \\
\text { geotechnical problems, } \\
\text { structural damage, } \\
\text { non-structural damage. }\end{array}$ \\
\hline $\begin{array}{l}\text { Chile } \\
(2010)\end{array}$ & $\begin{array}{l}\text { No damage or very } \\
\text { limited on the whole. } \\
\text { No restrictions on use. }\end{array}$ & $\begin{array}{l}\text { Structural or non- } \\
\text { structural damage } \\
\text { sufficient for controlled } \\
\text { risk to people. } \\
\text { Partial closure and } \\
\text { limited entry. }\end{array}$ & $\begin{array}{l}\text { Elevated damage } \\
\text { involving high risk of } \\
\text { injury to persons. } \\
\text { The building should be } \\
\text { closed. }\end{array}$ \\
\hline
\end{tabular}

Source: Authors, [9]. 
Table 4: Types of post-earthquake assessment and management.

\begin{tabular}{lcccccc}
\hline & $\begin{array}{c}\text { Japan } \\
(1986)\end{array}$ & $\begin{array}{c}\text { USA } \\
(1995)\end{array}$ & $\begin{array}{c}\text { Turkey } \\
(1999)\end{array}$ & $\begin{array}{c}\text { Italy } \\
(2000)\end{array}$ & $\begin{array}{c}\text { Colombia } \\
(2009)\end{array}$ & $\begin{array}{c}\text { Chile } \\
(2010)\end{array}$ \\
\hline $\begin{array}{l}\text { Evaluation of damage } \\
\text { and habitability }\end{array}$ & 2 times & 2 times & Sim. & Sim. & Sim. & Sim. \\
$\begin{array}{l}\text { No of formats in } \\
\text { building evaluation }\end{array}$ & 2 & 2 & 1 & 1 & 1 & 1 \\
$\begin{array}{l}\text { No of pages in form } \\
\text { Warnings in buildings }\end{array}$ & 2 & 1 & 3 & 3 & 2 & 2 \\
No of pages in manual & 141 & YES & YES & NO & YES & - \\
\hline
\end{tabular}

Source: Authors, [9].

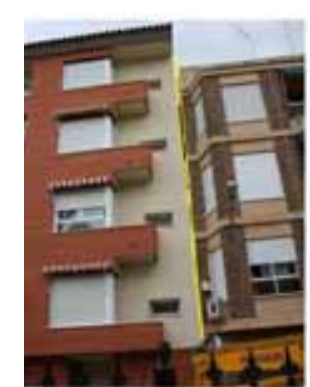

(a)

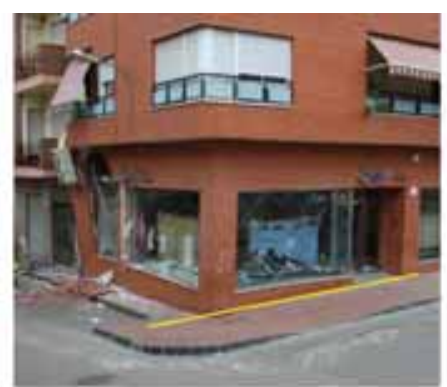

(b)

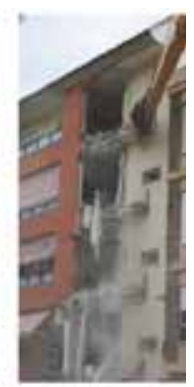

(c)

Figure 16: Condition of Grial building after the earthquake. (a) Separation of joints. (b) Settlement of foundations. (c) Start of enclosure demolition. Source: Authors, [9].

In the same way, we can see that in recent earthquakes with major damage in the urban centres the way of assessing damage and the post-earthquake management strategies differ considerably from one country to another (Table 4):

This heterogeneity of actions and the lack of standardized protocols for assessing damage were evident during the days after the earthquake in Lorca. The diversity of the criteria when cataloguing the level of damage and safety of each building gave rise to dangerous situations. An obvious case of this problem was the allegedly controlled demolition of the building called Grial in the neighbourhood of La Viña (Fig. 16). The building had, according to the rapid assessment report post-earthquake, various damages motivating its financial ruin. However, the report did not contemplate the possibility of an imminent collapse, allowing a traditional demolition that prompted the collapse of the building at its start-up. This unexpected incident destroyed a nearby church and seriously endangered the lives of the workers (Fig. 17).

The existence of a clear and simple standardized protocol for post-earthquake assessment in this situation would have helped a better diagnosis to be undertaken. Since then, the Polytechnic University of Cartagena has been working in this direction with the Ministry of Public Works and Planning of the Region of Murcia in the development of a form that would 


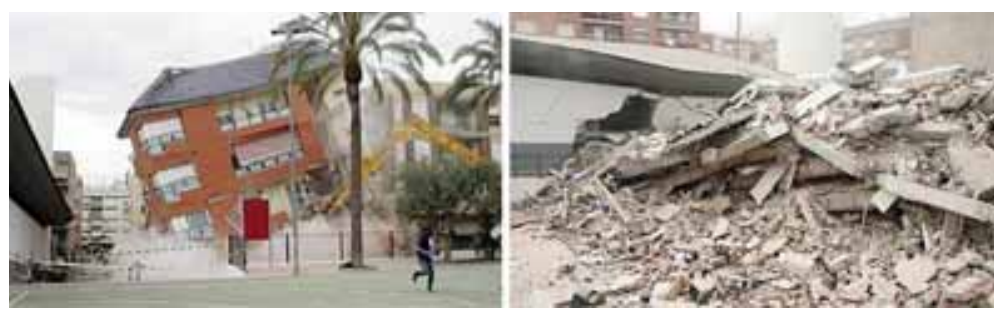

Figure 17: Unexpected collapse of the building (left) and fall onto the nearby church (right). Source: RTVE.

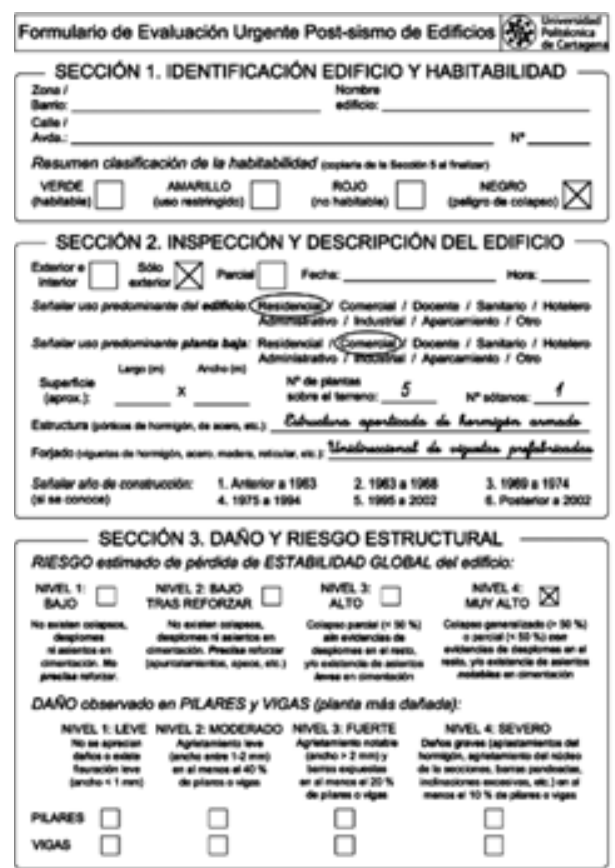

(a)

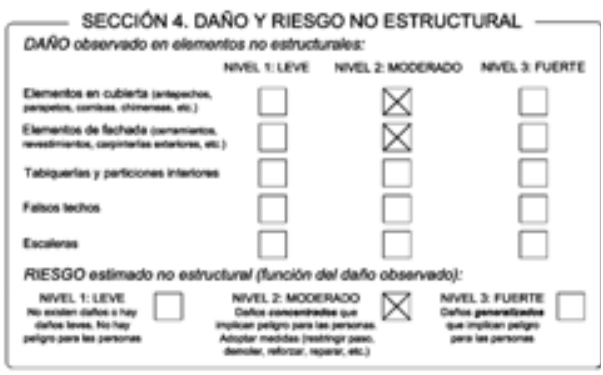

SECCION 5. CLASIFICACION DE LA HABITABILIDAD

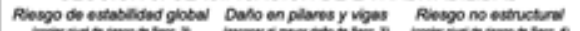

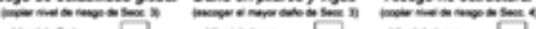

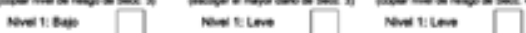

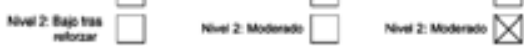

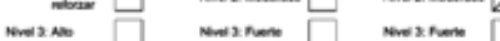

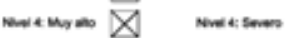

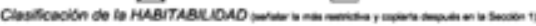

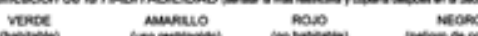

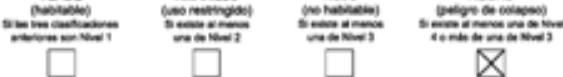

SECCION 6. DATOS DE CONTACTO Y CONENTARIOS

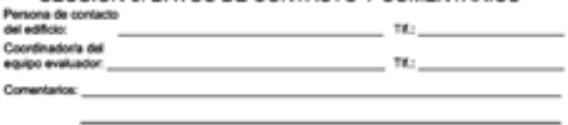

(b)

Figure 18: Building in danger of collapse. Completion of the proposed form. (a) Front. (b) Back. Source: Tomás A. [10].

be able to avoid these situations. An example of the results of this work is reflected in the following document (Fig. 18).

The form presents a set of boundaries after which the access to the building is prohibited or its demolition is required. In the previous building, there was an appreciable tilt of the building, which could have been accompanied by foundation settlement. On the ground floor the rotation of the columns was more clearly noticeable, although the overall appearance of the upper floors was very good.

According to the proposed form, which distinguishes between structural and non-structural damage, this building could be a level 4 (very high) of estimated risk of loss of global 
stability and level 2 (moderate) of non-structural risk. Therefore, it would be classified with danger of collapse (black colour), because there was at least one classification level 4. When estimating a level of very high risk of loss of global stability, no internal inspection would have been carried out according to the above form, directly ordering a cautious demolition.

\section{SEISMIC PLANNING AS A TERRITORIAL MANAGEMENT TOOL: THE NEW SISMIMUR PLAN AND THE URBAN MICROZONATION OF LORCA}

After the earthquake in the city of Lorca in 2011, the Region of Murcia government decided to instigate a new seismic strategic plan called SISMIMUR. This new plan has two main objectives. On the one hand, it should be able to avoid as far as possible most seismic vulnerability in the environment of the cities of the territory. The Region of Murcia is, as shown in Figs 3 and 4, a medium seismic risk area, with the possibility of lower-middle scale earthquakes. Nevertheless, it is poorly protected for these events, as evidenced by the extensive damage in the urban plot of Lorca. On the other hand, it is necessary to provide the technicians and professionals dealing with emergencies with clear and simple protocols for damage assessment.

For this purpose, the Ministry of Public Works and Planning of the Region of Murcia has drafted earthquake strategy guides [11]. There is a comprehensive technical manual structured in three parts. First, a guide exists with practical examples of the application of seismic regulations to make the complex seismic methodology affordable for all technical designers (architects, engineers, etc.). Second, there is a manual containing solutions and methodologies in the field of repairing earthquake-damaged structures. This is a dispersed and heterogeneous subject, which is usually not included in the standards and is often just solved under subjective criteria or the limited knowledge of the technicians. Thirdly and finally, a rapid assessment guide, which was being finalized at the time of writing this article. This last guide will collect methodologies of recognition and underpinning of structures damaged by earthquakes and will include a quick assessment post-earthquake form based on that shown in Fig. 18.

It is therefore intended that the experience gained in 2011, including the subsequent studies conducted in Lorca, are reflected in a new plan called SISMIMUR. The new plan should respect the following methodology for seismic risk assessment, taking into account the importance of the local effect in a city. The steps are as follows:

1. First, the seismic hazard throughout the Region of Murcia must be calculated, in order to determine the seismic action that represents the most probable movements in the area with return periods of 475 years and 975 years, in generic rock sites, and explicitly excluding the local effect (Fig. 19).

2. After the above analysis, we have to go a step further in the characterization of the movement, considering soil type at each point of the region, and including the contribution of the so-called 'local effect' in the estimation of motion parameters. This effect should be covered regionally, performing a geotechnical classification of the different soils that make up the Region of Murcia and assigning amplification factors to the different classes. Applying these factors, the pre-estimated rock movement must lead to estimations of the motion parameters being obtained and incorporate the aforementioned local effect, for different areas of the region.

3. The estimated motion is included as a seismic input, in order to estimate the seismic risk locally. This requires reducing the working scale from regional level to city level. It will require a microzonation study that includes building types in different areas of the city 

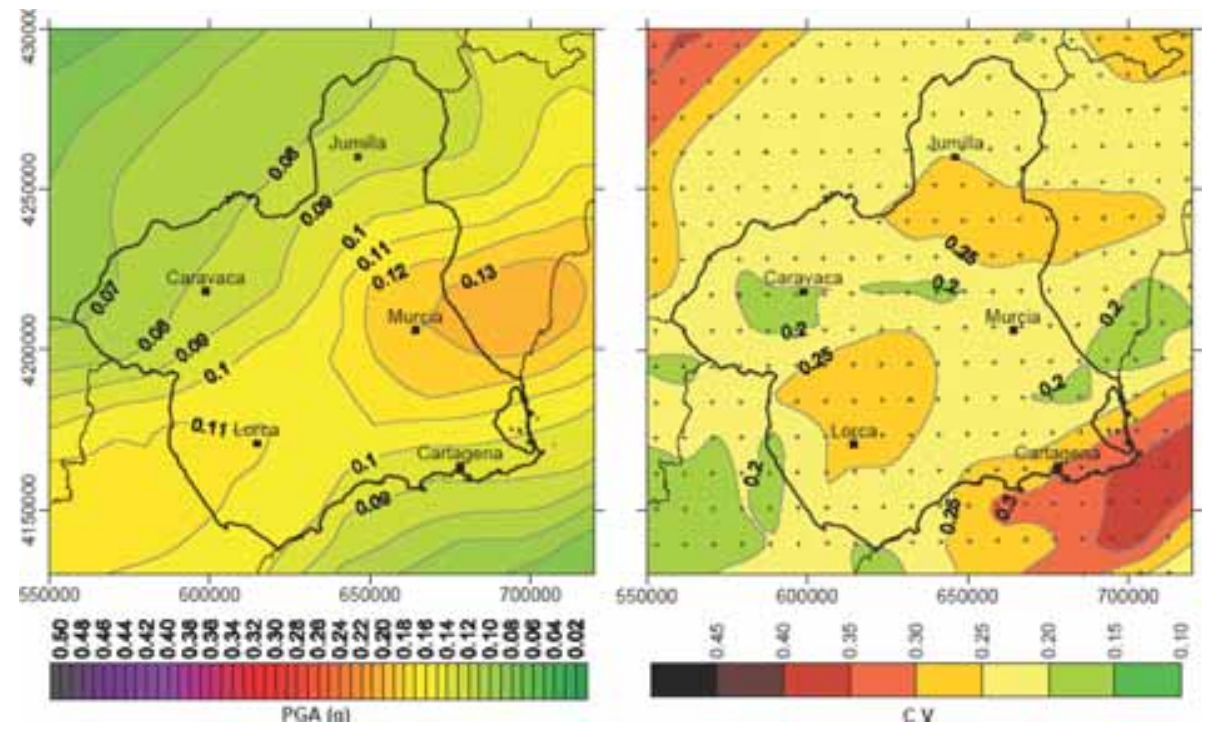

Figure 19: Map of PGA values in rock for a return period of 475 years (left) and corresponding to the coefficient of variation (right). Source: [12].

and more specifically its vulnerability to a certain seismic action. The vulnerability class assignment must been performed assessing the state of the urban plot of the city. This urban plot must range from historical old buildings to the urban expansion with technological building and the scheduled building land of the Urban General Plan. The Region of Murcia has a methodology to classify buildings in terms of vulnerability, according to macroseismic scale EMS 98 through the RISMUR project [8].

In this field, the new plan SISMIMUR includes innovative approaches in seismic planning in Spain, such as the implementation of urban planning instruments and regional management tools in order to decrease the seismic vulnerability of its growing cities. As a pilot project, the Ministry of Public Works and Territory of the Region of Murcia has commissioned the Technical University of Cartagena to develop an urban microzonation of the city of Lorca. This microzonation (the first one performed at a large scale in Spain) has established the vulnerabilities of the urban environment of the city of Lorca and its results will establish recommendations that must be implemented in the city's urban development instruments (Fig. 20).

4. These local data must be contrasted with data from RISMUR, a study aimed at identifying areas where the probability of occurrence of seismic activity has increased due to stress changes caused by previous earthquakes. In RISMUR, regional maps have been performed of the Coulomb static stress changes generated by the historical seismicity of magnitude Mw > 4.5, occurred in the Region of Murcia from 1000 to 2005 [12]. The interpretation of these maps has led to the identification of areas that have been overloaded by earthquake efforts in the last 80 years, which can be considered as an increase in the probability of the occurrence of new earthquakes (Fig. 21).

The results of these different steps must be put together at a later stage. It is in this last step when, by a weighted evaluation of the results, we must draw conclusions that have to be 


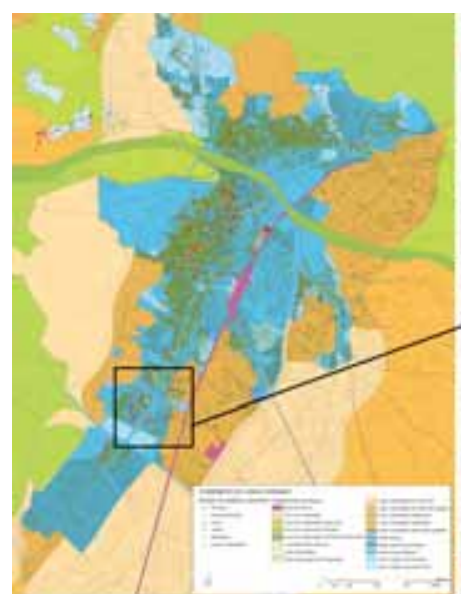

UPBAII PLAIUUUG (ZOHUIG)

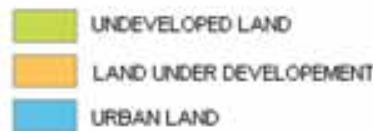

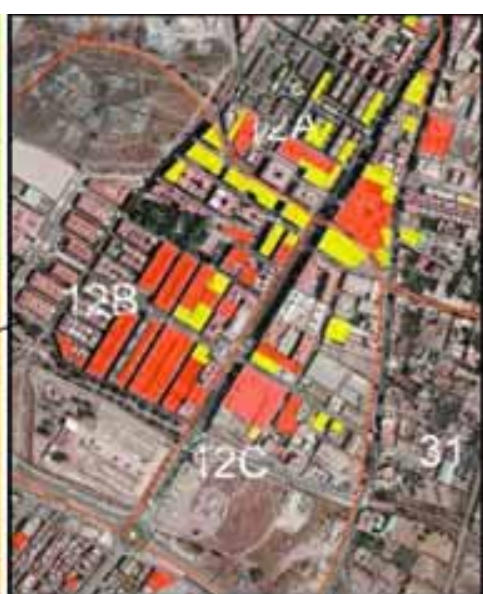

BULLEIG DAMAGE IIL LA VIIIA DASTRICT

BULDINO WTH FORBDDEN ACCESS

BULDING WTH AVERAGE DAMAGE

Figure 20: Urban microzonation: distribution of damage and vulnerability in Lorca urban planning schedule. Source: Authors, [9] (data from [13-15]).

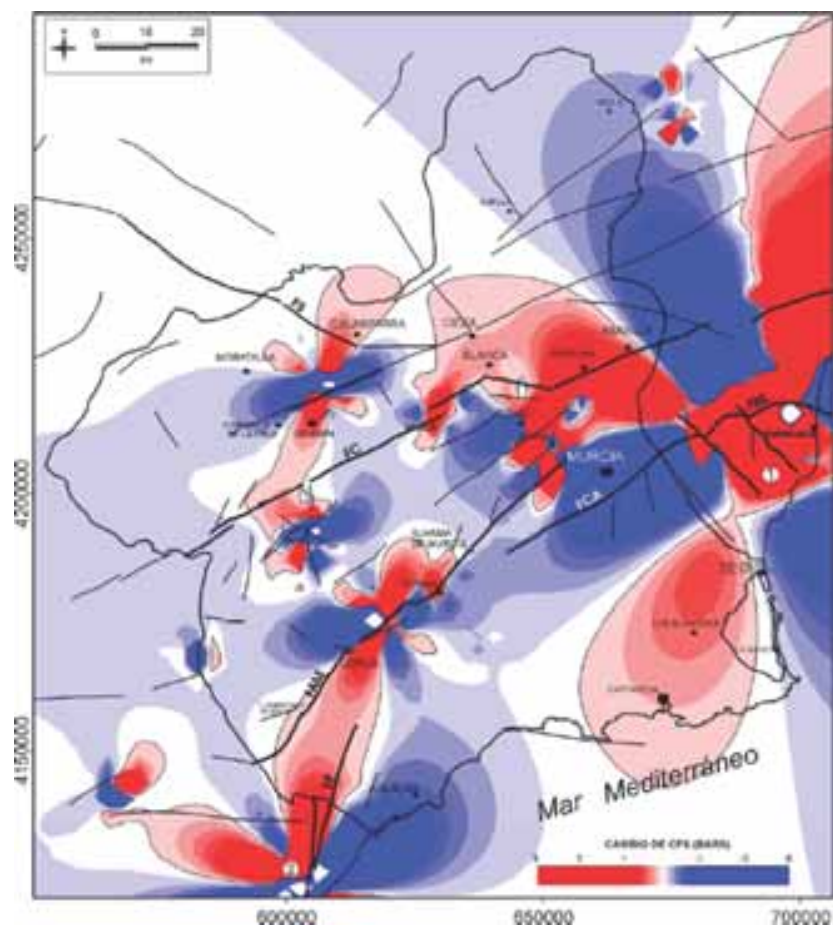

Figure 21: Map of seismic Coulomb static stress change induced in the Region of Murcia. Source: [12]. 


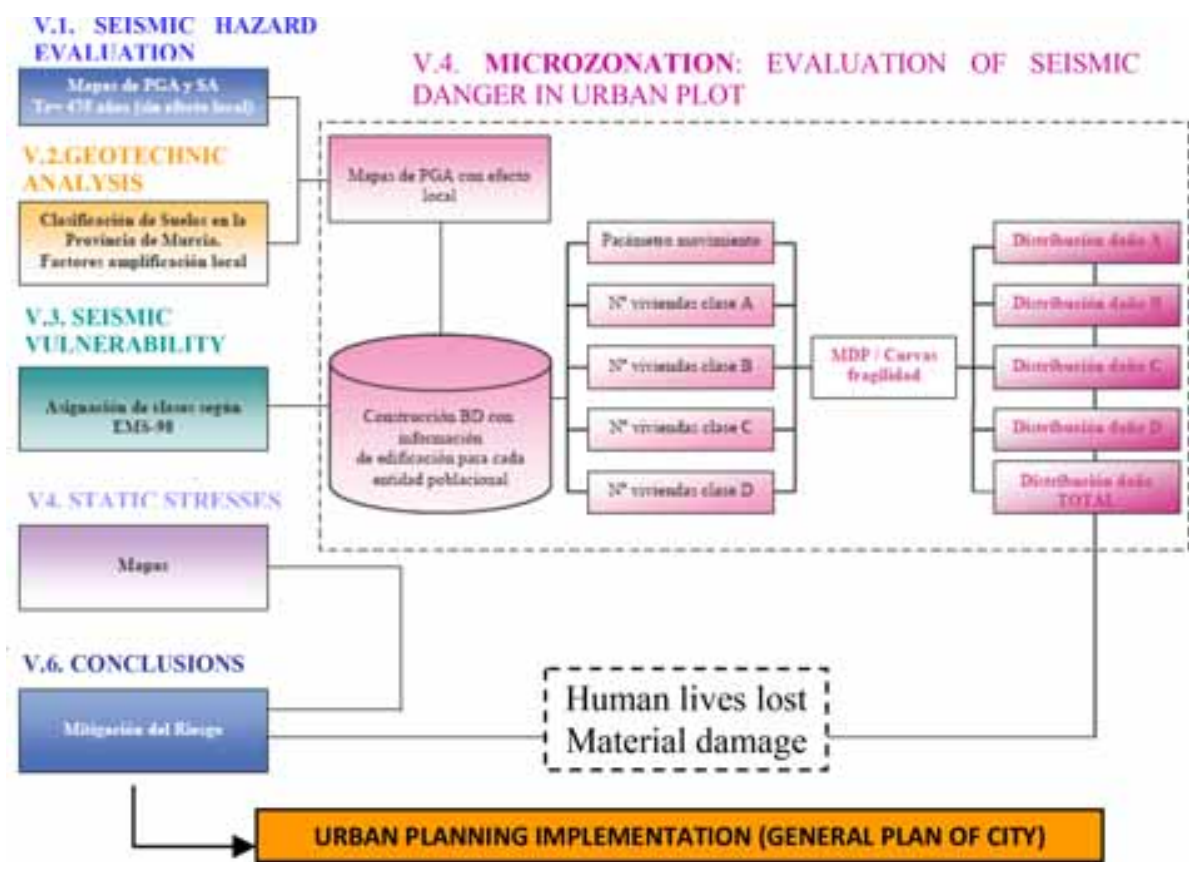

Figure 22: Summary of proposed vulnerability discovery process of the new SISMIMUR plan. Source: Authors. Modified from [2].

translated into practice through their implementation in maps with geospatial information systems (GIS). These graphical results must be integrated into the reviews of the General Urban Planning that guide the growth and development of the city in order to be executive [13]. This operation must include ordinances for construction aspects, and as a criteria level in the urban planning strategies for risk mitigation. The working diagram of the entire process is summarized in Fig. 22.

\section{CONCLUSIONS AND FUTURE PERFORMANCES}

The experience provided by the Lorca earthquake of May 11, 2011, brings us the following conclusions:

- The vast majority of loss of lives were not caused by the collapse of the structures, but from phenomena from other fields, such as inadequate geometric design of the building, inefficient constructive provisions during a shock, or an urban planning that favours adverse effects in case of earthquake.

- The earthquake damage was concentrated in structures and non-structural elements of buildings, not in the infrastructures of the city. These constructions therefore require a study that thoroughly investigates the vulnerability of the urban plot of a city and establishes a fast and secure protocol for evaluating post-earthquake damage in its real estate.

- Seismic planning must consider the so-called 'local effect'. This effect does not mean only to integrate seismic hazard amplification parameters or issues such as soil, but it means to reduce the territorial scale to the urban one, contemplating the distribution parameters of 
the urban plot or the characteristics of the housing stock in the city. The instrument necessary to achieve this level of detail is urban microzonation.

- It is necessary to implement, in urban planning tools of cities with some risk of earthquake, the seismic planning variable at all levels. Lorca is an obvious example of how the absence of these parameters in urban planning development accentuates the damage of buildings for an earthquake of medium-low intensity.

\section{REFERENCES}

[1] Geological and Mining Institute of Spain, Preliminary Geological Report Lorca Earthquake of May 11, 2011, 5.1 Mw. Ministry of Science and Innovation: Madrid, 2011.

[2] General Directorate of Civil Protection, Civil Protection Special Plan to the Seismic Risk in the Region of Murcia (SISMIMUR). Department of the Presidency of the Region of Murcia: Murcia, Spain, 2006.

[3] Seismic Standards Standing Committee, Seismic Construction Standard: General and Building (NCSE-02). Ministry of Development: Madrid, 2002.

[4] Seismic Standards Standing Committee, Seismic Construction Standard: General and Building (NCSE-94). Ministry of Development: Madrid, 1994.

[5] Seismic Standards Standing Committee, Seismic Construction Standard: General and Building (PGS-1). Ministry of Development: Madrid, 1968.

[6] Seismic Standards Standing Committee, Seismic Construction Standard: General and Building MV-101. Ministry of Development: Madrid, 1962.

[7] Council of Lorca, General Urban Plan of Lorca. Lorca, Spain, 2007.

[8] Murphy, P., Project Sismozon. Ministry of Science and Innovation: Madrid, 2011.

[9] García-Ayllón, S. \& Tomas, A., Actions, diagnosis and territorial management of the disaster in the city of Lorca after earthquake of May 11, 2011. Disaster Management and Human Health Risk III, Vol. 133, WIT Press: Southampton, 2013.

[10] Tomás, A. \& Díaz, E., Proposal of a Form for Post-Earthquake Rapid Evaluation of Buildings. Internal report, Department of Civil Engineering, Technical University of Cartagena (UPCT): Cartagena, Spain, 2013.

[11] Department of Public Works and Planning of the Region of Murcia, Guidelines for the Definition of an Antiseismic Strategy. FHECOR Knowledge: Murcia, Spain, 2012.

[12] Geological and Mining Institute of Spain and General Directorate of Civil Protection, Project RISMUR: Seismic Risk in the Region of Murcia. Department of the Presidency of the Region of Murcia: Murcia, Spain, 2006.

[13] Lorca Town Hall. SIT Lorca. http://www.lorca.es/sitlorca/sitlorca.asp

[14] Department of Public Works of the Region of Murcia. Office for Lorca Reconstruction. http://www.carm.es/web/pagina?IDCONTENIDO=30081\&IDTIPO=100\&RASTRO= c1079\$m

[15] Lorca Town Hall. Lorca Earthquake 11 May Geographic Viewer. http://www.lorca.es/ seismo11demayo/seismo11 demayo.asp?id=1540 